\title{
Tissue hyperplasia following placement of a biode- gradable stent for a refractory esophageal stricture: treatment with argon plasma coagulation
}

A 36-year-old woman presented with high grade peptic stenosis in the distal esophagus ( $\bullet$ Fig. 1). After three consecutive sessions of steroid injection/dilation with disappointing results, a biodegradable polydioxanone esophageal stent (SXElla-BD, 25×80 mm; Ella-CS, r.s.o., Hradec Kràlové, Czech Republic) was inserted ( $\bullet$ Fig. 2). The patient experienced retrosternal pain for a short period of time after the intervention, but otherwise she had an uneventful recovery and was discharged 48 hours after the intervention. The patient was kept on high dose proton pump inhibitor treatment and had almost complete resolution of dysphagia. At 4 months after stent insertion the patient presented with recurrent dysphagia. A repeat endoscopy showed the partially degraded stent, with hyperplastic tissue at the proximal end, resulting in severe stenosis ( Fig.3). The stenosis was treated with argon plasma coagulation ( Fig.4). On follow-up endoscopy 10 months after stent insertion, the tissue hyperplasia had largely subsided ( $\bullet$ Fig. 5 a) and the stenosis had resolved completely ( $\mathbf{F i g . 5 b}$ ). The patient continues to remain symptom-free since over 18 months.

Recently, self-expanding pH-dependent biodegradable polydioxanone stents have become available for the treatment of refractory peptic esophageal stenosis [1]. These stents confer a continuous dilatation force over a longer time period, while avoiding repeat endoscopy for stent removal. However, experience with these stents is still limited [2] and cases of severe tissue hyperplasia resulting in recurrent dysphagia have been described [3]. To alleviate symptoms, endoscopic balloon dilation [3] or the temporary implantation of a second self-expanding plastic stent have been reported [4]. The present case report adds argon plasma coagulation as another possible treatment option. This treatment seems to be particularly suited because of its low complication rate [5], and the tissue hyperplasia will eventually subside after complete degradation of the stent.

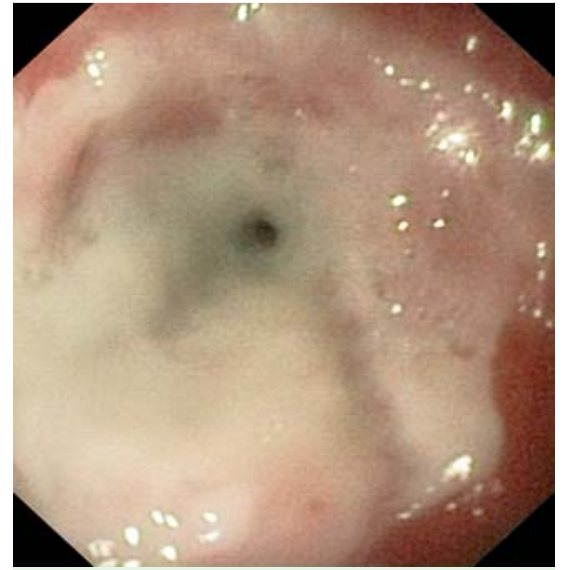

Fig. 1 Initial endoscopic aspect of stenosis of the distal esophagus in a 36-year-old woman presenting with high grade peptic stenosis.

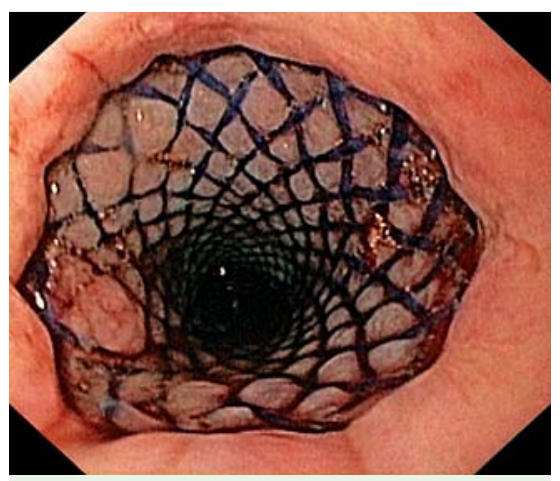

Fig. 2 View immediately after insertion of the biodegradable stent.

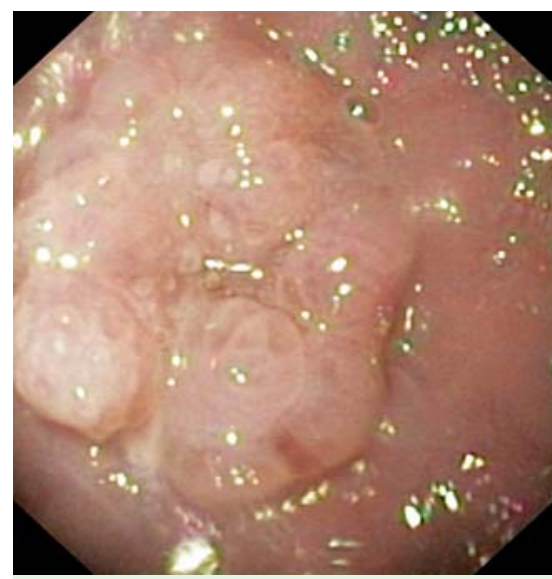

Fig. 3 Severe stenosis at the proximal stent entrance.

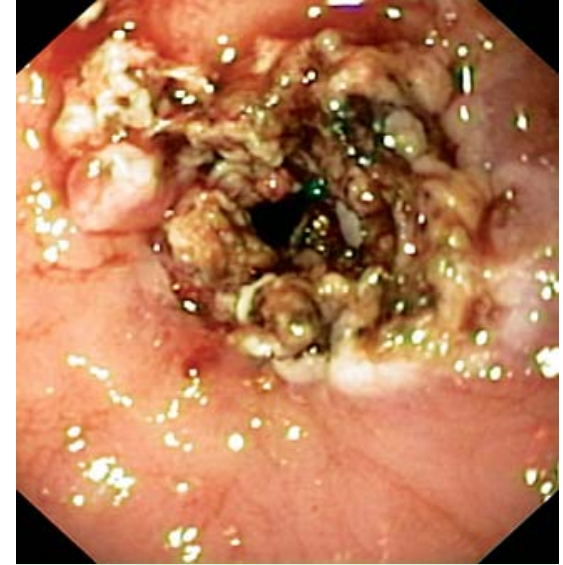

Fig.4 Proximal stent entrance after argon plasma coagulation.
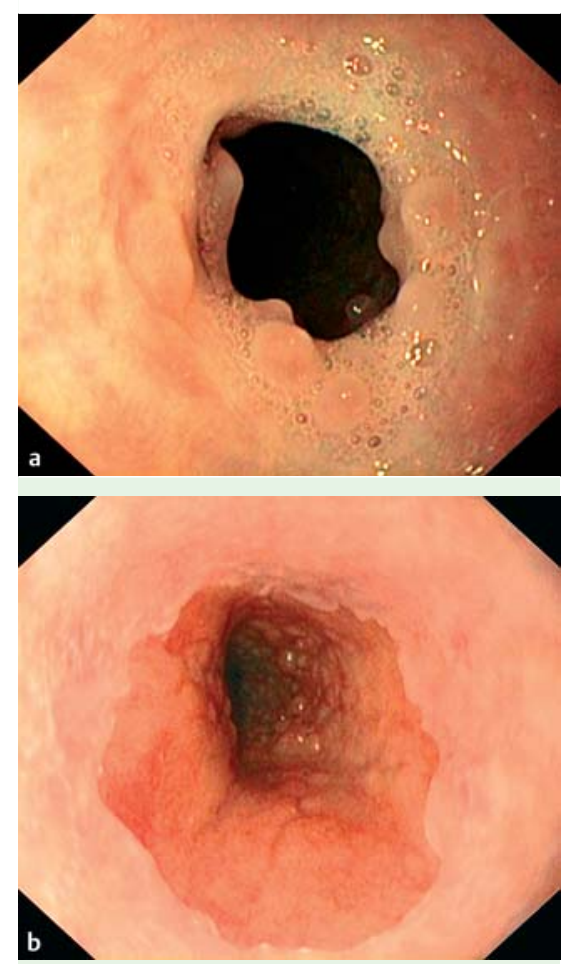

Fig. 5 Final result 10 months after stent insertion. a The proximal stent entrance. b Site of the initial peptic stenosis. 
Endoscopy_UCTN_Code_TTT_1AO_2AZ

Competing interests: None

\section{F. L. Dumoulin ${ }^{1}$, D. Plassmann²}

${ }^{1}$ Department of Medicine, Gemeinschaftskrankenhaus Bonn, Bonner Talweg, Bonn, Germany

2 Office Internal Medicine and Gastroenterology, Münsterstraße, Bonn, Germany

\section{References}

1 van Hooft JE, van Berge Henegouwen MI, Rauws EA et al. Endoscopic treatment of benign anastomotic esophagogastric strictures with a biodegradable stent. Gastrointest Endosc 2011; 73: $1043-1047$

2 Repici A, Vleggaar FP, Hassan C et al. Efficacy and safety of biodegradable stents for refractory benign esophageal strictures: the BEST (Biodegradable Esophageal Stent) study. Gastrointest Endosc 2010; 72: 927-934

3 Hair CS, Devonshire DA. Severe hyperplastic tissue stenosis of a novel biodegradable esophageal stent and subsequent successful management with high-pressure balloon dilation. Endoscopy 2010; 42: E132-133

4 Conio M, Blanchi S, Filiberti R, De Ceglie A. Self-expanding plastic stent to palliate symptomatic tissue in/overgrowth after self-expanding metal stent placement for esophageal cancer. Dis Esophagus 2010; 23: 590-596

5 Manner H. Argon plasma coagulation therapy. Curr Opin Gastroenterol 2008; 24: $612-616$

\section{Bibliography}

Dol http://dx.doi.org/ 10.1055/s-0032-1310021 Endoscopy 2012; 44: E356-E357

(c) Georg Thieme Verlag KG Stuttgart · New York ISSN 0013-726X

\section{Corresponding author}

\section{Professor F. L. Dumoulin}

Department of Medicine Gemeinschaftskrankenhaus Bonn Bonner Talweg 4-6

D-53113 Bonn

Germany

Fax: +49-228-5081562

f.dumoulin@gk-bonn.de 